Research Paper

\title{
Understanding the Reasons for Variations in Luminescence Sensitivity of Natural Quartz Using Spectroscopic and Chemical Studies
}

\author{
SUCHINDER K SHARMA ${ }^{1, \dagger, *}$, SANTA CHAWLA ${ }^{2}$, M D SASTRY $^{3}$, MAHESH GAONKAR $^{3}$, SANDESH $^{2}$ \\ MANE $^{3}$, V BALARAM ${ }^{4}$ AND ASHOK K SINGHVI ${ }^{1}$ \\ ${ }^{1}$ AMOPH Division, Physical Research Laboratory, Ahmedabad, 380 009, India \\ ${ }^{2}$ National Physical Laboratory, Dr. K.S. Krishnan Road, New Delhi 110 012, India \\ ${ }^{3}$ Gemmological Institute of India, Opera House, Mumbai 400 007, India \\ ${ }^{4}$ CSIR-National Geophysical Research Institute, Hyderabad 500 007, India
}

(Received on 19 December 2016; Revised on 24 April 2017; Accepted on 05 May 2017)

\begin{abstract}
Natural quartz from diverse provenances exhibit variations in their luminescence sensitivity (photon flux/mg.Gy) that span over ten orders of magnitude. A range of factors (such as crystallization/recrystallization process, irradiation, thermal and optical history) that modify luminescence sensitivity have been considered to explain such differences in luminescence sensitivity. However, a clearly definable/identifiable reason is still awaited; such as, these large variations in luminescence sensitivity are related to commonly occurring luminescence quenchers/enhancers in natural quartz lattice. Towards this, quartz mineral grains extracts from different provenances and from varied depositional environments were examined spectroscopically using Fourier Transform infra-red spectroscopy (FTIR), optically stimulated luminescence (OSL), photoluminescence (PL), time resolved PL (TRPL) decay, thermoluminescence (TL) and the trace element analysis. The present study exhibited an anti-correlation between OSL sensitivity and water content in quartz (estimated through integrated intensity of normalized FTIR signal in the wave number region $3000-3600 \mathrm{~cm}^{-1}$ ), such that a sensitivity change of over 5 orders of magnitude corresponded to a change in integrated water absorption signal by 5 times, but in opposite direction. PL and TRPL results enabled further insights.
\end{abstract}

Keywords: Quartz; Luminescence Sensitivity; Lattice Defect; Thermoluminescence; BLSL

\section{Introduction}

Thermoluminescence (TL) and optically stimulated Luminescence (OSL) of natural quartz grain extracts from geological deposits have been the workhorse for retrospective dosimetry and geochronology (see, Boetter Jensen et al., 2003). TL/OSL are radiation induced phenomena and arise due to the presence of defects in the crystal lattice that serve as charge traps/ reservoirs. These reservoirs are populated by free charges created by irradiation of quartz by ionizing radiation. The trapped charges can be depopulated by optical and/or thermal stimulation. Some of these de-trapped charges recombine radiatively at a suitable defect site to give OSL and TL. The spectral nature of the emitted light is characteristic of the recombination centre and the intensity of emitted luminescence is proportional to the number of trapped charges, i.e. the radiation dose up to a limiting saturation value. The proportionality constant between radiation dose and luminescence output is luminescence sensitivity given as luminescence/unit dose/unit mass.

Natural quartz $\left(\mathrm{SiO}_{2}\right)$ originates from metamorphic and sedimentary rocks. In nature, áquartz exists in abundance, in which, the corner sharing linked $\mathrm{SiO}_{4}$-tetrahedra form the crystalline structure. Though quartz is nearly $100 \% \mathrm{SiO}_{2}$, it contains trace impurities such as aluminium, iron, hydrogen (in the form of $\mathrm{OH}$ ) and intrinsic defects like vacancies and interstitials, [Preusser et al., 2009; Bottern-Jensen et

*Author for Correspondence: E-mail: suchindersharma@gmail.com

'Present address: Department of Chemistry and Chemical Engineering, Chalmers University of Technology, 41296 Göteborg, Sweden 
$a l .$, 2004]. The nature and concentration of such defects in quartz is determined by the physical, chemical, and the thermal environments during crystallization. Formation of metamorphic quartz occurs by a mineral reaction at elevated temperatures, higher pressures and in the presence of water. Crystallization from precursor aqueous solution at a temperature higher than the surrounding bedrock gives hydrothermal quartz.

A proper explanation of the variability of luminescence sensitivity between individual grains/ samples by up to ten orders of magnitude or even more has been elusive. Such variation in luminescence sensitivity of natural quartz can arise due to: a) physico-chemical and thermal environment during crystallization, and b) treatments like heating, photobleaching and irradiation in the nature or in the laboratory. These lead to the charge-transfer between defects and/or the formation of new centres that modulate charge trapping/recombination process. Sawakuchi et al. [2011] reported that quartz samples from rocks, with higher crystallization temperature had higher luminescence-sensitivity and those from hydrothermal rocks had lower luminescence sensitivity. Low sensitivity in quartz from crystalline rocks has been explained via hole-transfer between recombination centres [Chithambo et al., 2007]. Boetter-Jensen et al. [1995] studied the variation in luminescence sensitivity of quartz with annealing prior to irradiation at temperatures $\left(300-1000^{\circ} \mathrm{C}\right)$ and observed an increase in the OSL sensitivity through supra-linearity in the dose response curve. Mckeever [1984] and Preusser et al. [2009] collate basic information in this regard.

TL glow curve of natural quartz samples can exhibit up to 10 glow peaks in the temperature region $-110^{\circ} \mathrm{C}$ and $400^{\circ} \mathrm{C}$ [Medlin, 1968]. TL emission bands span three spectral domains: a) high orange/red emission; b) orange/red and blue/blue-green emission of comparable intensities; and c) high blue/blue-green emission [Kuhn et al., 2000]. It is suggested that TL at $470 \mathrm{~nm}$ corresponds to $\left[\mathrm{AlO}_{4}\right]^{\circ}$ centers. The emission between $250-400 \mathrm{~nm}$ is due to electron recombination with holes trapped at $\left[\mathrm{AlO}_{4}\right]^{\circ}$ centers [Martini et al. $(1995,2009)]$ and $\left[\mathrm{AlO}_{4} /(\text { alkali ion })^{+}\right]$ centers [Vartanian et al., 2000]. TL emission at 395 $\mathrm{nm}$ corresponds to $\left[\mathrm{H}_{3} \mathrm{O}_{4}\right]^{\circ}$ hole-center, Martini et al. [1995] and Yang and Mckeever [1990(a,b)].
Reviews by Krbetschek et al. [1997] and Gotze et al. [2001] provide detailed description on the spectral emissions from quartz with different colours. Han et al. [1997] reported an anti-correlation between luminescence sensitivity of quartz grains extracted from rocks and their crystallization ages. In natural and synthetic quartz samples, Takashi et al. [2006] reported, a) negative correlation between blue-TL and $\mathrm{Al}$ concentration, and $\mathrm{b}$ ) an increase in the luminescence sensitivities of red TL and OSL with Al content > 300 ppm. Rink [1994] used quartz samples of 25-1040 million year age and concluded that the luminescence pathways get altered over geologic times. To further understand the reasons for variability in luminescence sensitivity of quartz, the present work investigated OSL sensitivity of quartz grains from different provenances that had widely varied crystal growth and weathering environments.

OSL sensitivity was variable between samples and between grains within a sample. Both cases were examined. Luminescence sensitivity was computed as number of photons emitted per unit irradiation dose per unit mass and variation implies that with the same irradiation and thermal history, different quartz grains emit widely varied number of photons. This implies a competition between radiative and non-radiative recombination pathways. Quartz grains where nonradiative processes dominate would produce lesser number of photons upon stimulation. Since hydroxyl group and water have shown to provide non-radiative pathways in luminescent materials [Rink, 1994], FTIR spectroscopy was used to provide a measure of water content in quartz grains. Other spectroscopic techniques such as OSL, PL, time resolved decay of PL and TL were also used. Based on the results, a model is proposed that explains (a) varied luminescence sensitivity of quartz, and (b) the increase in luminescence sensitivity upon an irradiation and heating.

\section{Materials and Methods}

The sampling sites are listed in Table 1. Quartz grains $(180 \pm 30 \mu \mathrm{m})$ from the sediments were extracted using standard chemical procedures and their purity against feldspar contamination/inclusions was checked using infra-red stimulated luminescence (IRSL). The OSL sensitivity of individual grain was measured in a single grain Ris $\varnothing$ TL/OSL reader using a constant test dose of $10 \mathrm{~Gy}$. 
Table 1: Sampling sites for quartz samples

\begin{tabular}{|c|c|c|}
\hline S.No. & Sample location & Sample Code \\
\hline 1 & Nigeria, Africa: Sahara desert sand & PASMI-6 \\
\hline 2 & $\begin{array}{l}\text { Abudhabi, United Arab Emirates: } \\
\text { Wahiba sands }\end{array}$ & GLAT \\
\hline 3 & $\begin{array}{l}\text { Kachhch, Gujarat, India: Fluvial } \\
\text { samples Allah Bund }\end{array}$ & PCMA-16 \\
\hline 4 & Tamilnadu, India: Tsunami sand & $\mathrm{TN} 8$ \\
\hline 5 & Australia: Dark Brook River sand & DBC -14 \\
\hline 6 & $\begin{array}{l}\text { Alaknanda river, Himalaya, North India: } \\
\text { Fluvial samples }\end{array}$ & $\mathrm{KH} 21$ \\
\hline 7 & Didwana, Rajasthan, India: Desert sand & $\mathrm{R}-16$ \\
\hline 8 & $\begin{array}{l}\text { Mauritania, Western-North Africa: } \\
\text { Dune sands }\end{array}$ & KLMS \\
\hline 9 & Pushkar, India: Dune sands & TL-14 \\
\hline 10 & Chennai, India: Tsunami sand & PF2ST2 \\
\hline 11 & Czech Republic: Fluvial sands & SP84 \\
\hline 12 & $\begin{array}{l}\text { Standard Quartz Sample from Riso, } \\
\text { Denmark }\end{array}$ & \\
\hline
\end{tabular}

The excitation was using a $532 \mathrm{~nm}$ laser and the detection channel comprised EMI 9235 QA (bialkali type) photomultiplier tube (PMT). Based on the green-light stimulated luminescence sensitivity of each grain, the grains were separated into two groups; dull quartz $(<150$ photons/s/grain as initial OSL intensity) and bright quartz ( $>150$ photons/s/grain). Individual bright or dull grains were then picked-up manually (from discs used for single grain) using a indigenously developed system with a capillary linked to a vacuum suction device. Several sets of dull and bright quartz grains were prepared with at least 1000 grains in each set. These were used for spectroscopic studies. This procedure removed any bias that could arise from the source of samples and the only important variable here was the sensitivity. An implicit and reasonable assumption in these studies was that the variation in luminescence sensitivity due to grain volume (mass) did not affect any of the conclusions. The change in volume over the grain size range was $\sim 15 \%$, whereas, the change in sensitivity was five to six orders of magnitude.

Trace impurity concentration was determined using an Perkin Elmer Sciex ELAN DRC II, inductively coupled plasma mass spectrometer (ICPMS) and the analysis followed the procedure by Roy et al. [2007]. Photoluminescence (PL) excitation and emission spectra and photoluminescence decay of UV violet emission used for OSL dating were measured using a combined steady state fluorescence spectrometer (Edinburgh Instruments FLSP920). For PL measurements, the excitation source was a continuous Xenon lamp (450W; emission range of 230$2000 \mathrm{~nm}$ ) with 1800 groves/mm single-grating excitation/emission monochromator and for decay measurements, the source was a pulsed Xe lamp. The measurements were performed on samples packed in the groove of sample holder at room temperature and the results were normalized to their weights. FTIR measurements in $400-4000 \mathrm{~cm}^{-1}$ range were in a diffuse reflectance mode using a Nicolet 6700 FTIR spectrometer.

\section{Results and Discussion}

Trace element analysis results are presented in supplementary Table S1. In this table, the samples are listed in the order of their increasing OSL sensitivity (Row 1, Table 2). Results for calibration quartz (from Ris $\varnothing$ National Laboratory, Denmark) are also presented for comparison. The samples showed the presence of transition-metal ions $(\mathrm{Cr}, \mathrm{Ni}, \mathrm{Cu}$, etc.) and lanthanides ( $\mathrm{La}, \mathrm{Ce}, \mathrm{Nd}, \mathrm{Tb}$, etc.). We examined possible correlation of sensitivity with each of the impurities but no clear trend could be seen, supplementary Figure S1. It suggests that these metallic impurities, which include $\mathrm{Fe}$, a common luminescence quencher, do not play a direct role in determining the luminescence sensitivity. Any cumulative role of different impurities however cannot be evaluated at this stage.

\section{Fourier Transform Infra-Red (FTIR) Spectroscopy}

FTIR spectra of quartz samples in $2000-4000 \mathrm{~cm}^{-1}$ range is given in Fig. 1. The peaks were normalized for 2130-2240 $\mathrm{cm}^{-1}$ quartz bands (matrix signals). Using this normalization, the total water content was quantified using a broad band between 3000 and 3600 $\mathrm{cm}^{-1}$ due to total water content and a peak around $3420 \mathrm{~cm}^{-1}$ is due to molecular $\mathrm{H}_{2} \mathrm{O}$.

Figure 2 gives the variation in FTIR spectra between separated dull and bright quartz grains within the same sample aliquots of four different samples. Separated bright grains exhibited less intense IR- 


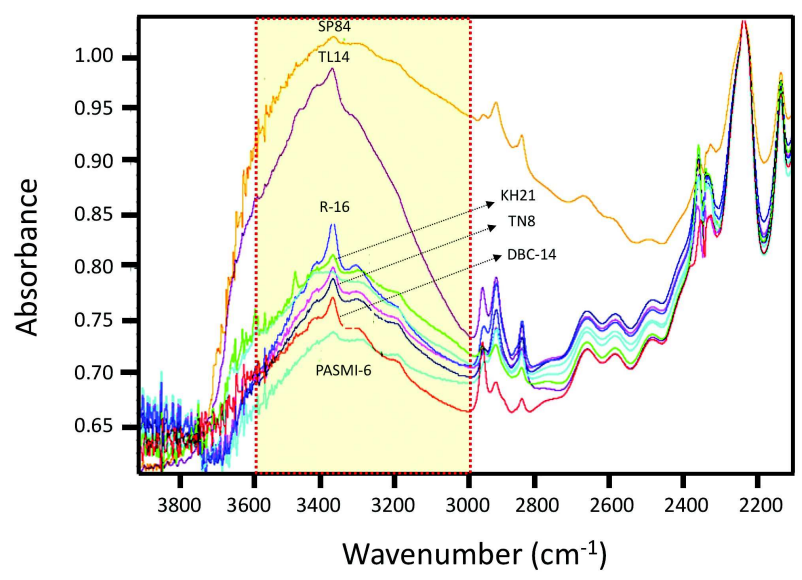

Fig. 1: FTIR spectra of different quartz samples
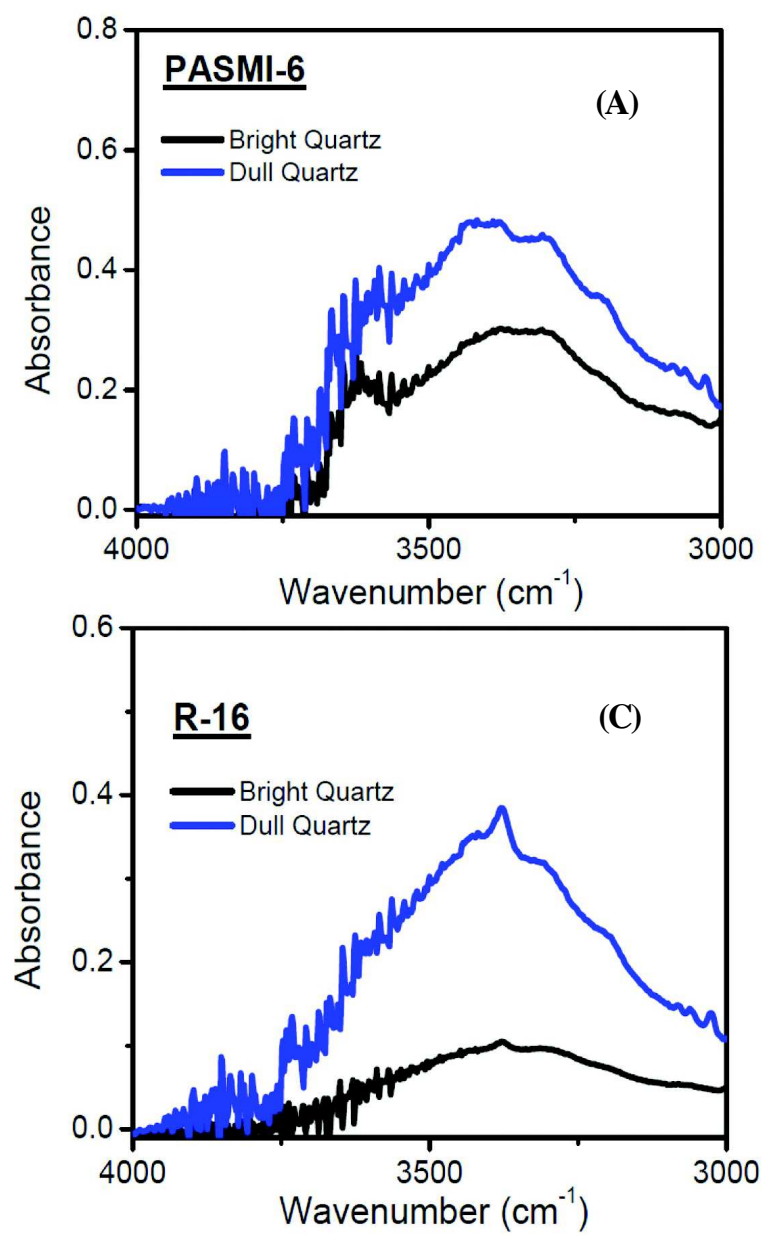

sand). The difference between absorption intensities between dull and bright samples suggests a role of water in determining the sensitivity of quartz. A plot of fraction of bright grains in samples with its water absorbance is shown in Fig. 3. It shows that the samples with high lattice water content contained fewer bright grains, while the sample, with low lattice water content had larger number of bright grains, e.g., PASMI-6 shows maximum bright grains and least water absorption. Signal corresponding to $3420 \mathrm{~cm}^{-1}$ line also depicted a similar trend but, due to uncertainties in its determination under a large background signal, it could not be explored further. It is to be remembered here that the samples were dried
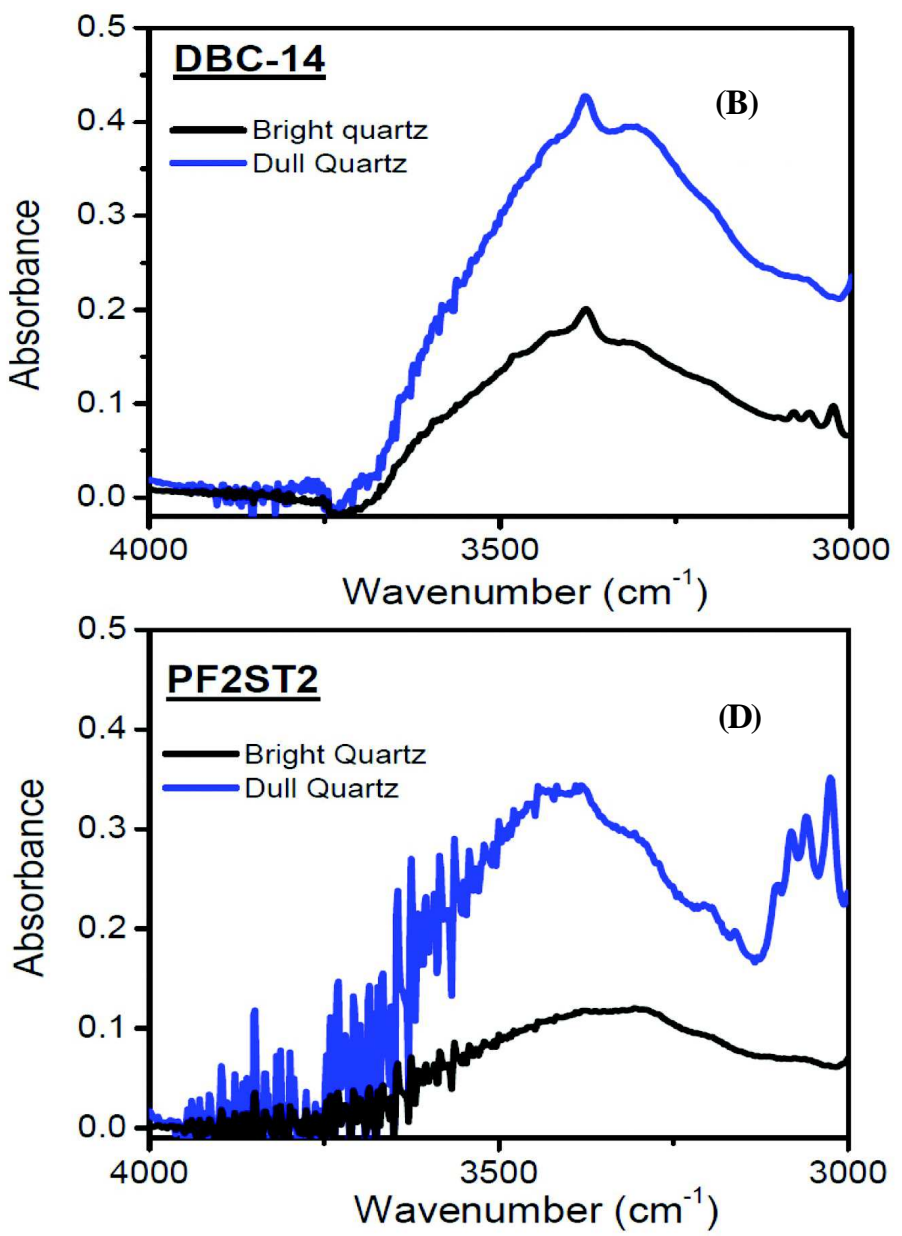

Fig. 2: (A-D): FTIR spectra comparison between separated dull and bright samples in $3000-3600 \mathrm{~cm}^{-1} \mathrm{region}^{-1}$ decreasing order of their luminescence sensitivity. Separated bright samples showed low water content, whereas, high water amount could be observed for dull samples

absorption and the dull grain samples gave more intense IR-absorption. The lowest water absorbance is shown by the sample PASMI-6 (Sahara desert at $50^{\circ} \mathrm{C}$ for $24 \mathrm{~h}$ prior to measuring FTIR spectra to remove any of the surface effect. 


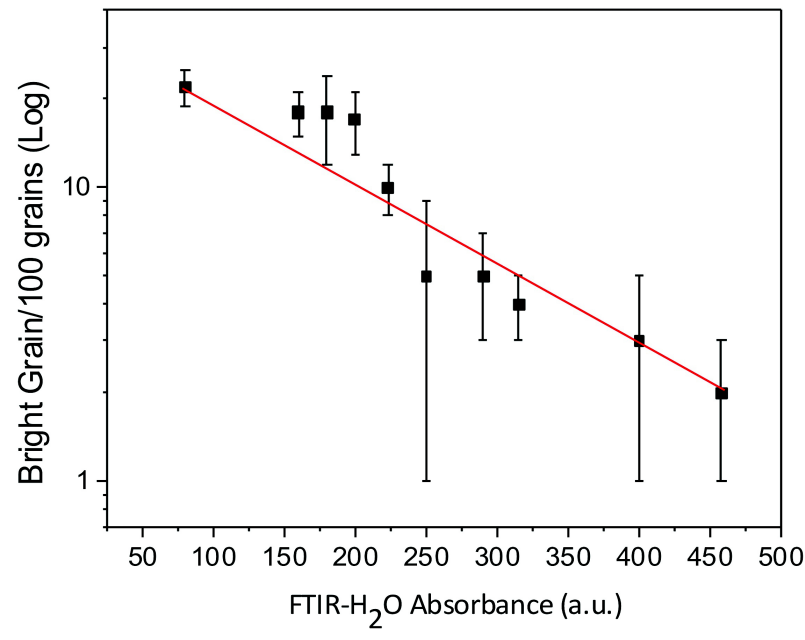

Fig. 3: Number of Bright grains for each set of 100 grains as a function of water content in quartz lattice. Higher the water content in quartz lattice, lesser the number of bright grains in each set of sample

\section{OSL Sensitivity and Correlation with Water Content}

Variation of measured continuous-wave OSL sensitivity (photon counts/s.mg.Gy) and integrated area in 3000-3600 $\mathrm{cm}^{-1}$ absorbance is shown in Fig. 4. The trend indicates an anti-correlation, i.e., low sensitivity samples had maximum absorbance in 3000$3600 \mathrm{~cm}^{-1}$ region and the high sensitivity sample showed lowest absorbance. The trend implies that the luminescence emission gets increasingly quenched with the presence of water. Present results suggested that the water content in quartz lattice provide nonradiative pathways of recombination. The combined results are presented in supplementary Fig. S2. A

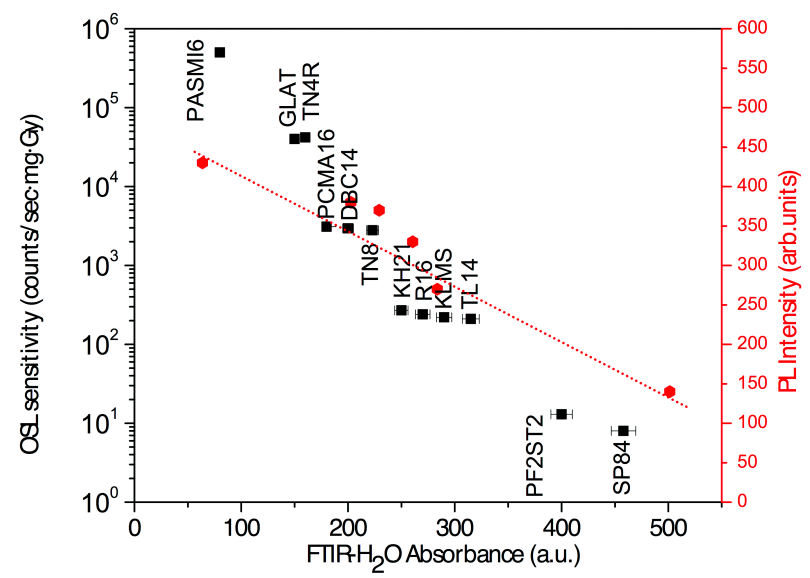

Fig. 4: Anti-correlation between total water absorbance obtained through FTIR $\left(3000-3600 \mathrm{~cm}^{-1}\right)$ and BLSL sensitivity. Here black squares refer to OSL sensitivity and red squares refer to $P L$ intensity typical TL glow curve and BLSL decay curve for quartz is shown in the supplementary Fig. S3.

\section{Photoluminescence (PL) Spectroscopy}

PL characteristics of an emitting material is determined by the nature of defect centres and PL is quenched through water content $\left(\mathrm{OH}^{-}\right.$bond) [Yang and Mckeever, 1988]. Relative efficiencies of different wavelengths of incident light to excite electron from ground state to their excited states is termed as "excitation spectrum" while, the relative distribution of various wavelengths in the light emitted after excitation by a single wavelength is termed as "emission spectra". Because of their novel electronic configuration, each impurity ion has characteristic spectrum for excitation and emission.

PL spectra corresponding to OSL emission wavelength $(395 \mathrm{~nm})$ were measured at room temperature for all the samples, under identical experimental conditions. The PL intensities of samples were weight normalized for comparison. PL excitation spectra monitored at $395 \mathrm{~nm}$ emission shows a peak at $242 \mathrm{~nm}$ (Fig. 5 inset). PL emission spectra following excitation at $242 \mathrm{~nm}$ wavelength, gave a prominent emission band at $395 \mathrm{~nm}$, with much smaller broad peak at $760 \mathrm{~nm}$ (Fig. 5).

Emission-band at $395 \mathrm{~nm}$ is due to $\mathrm{H}_{3} \mathrm{O}_{4}{ }^{\circ}$-type recombination centres and correspond to the OSL emission wavelength [Yang and Mckeever, 1988]. The

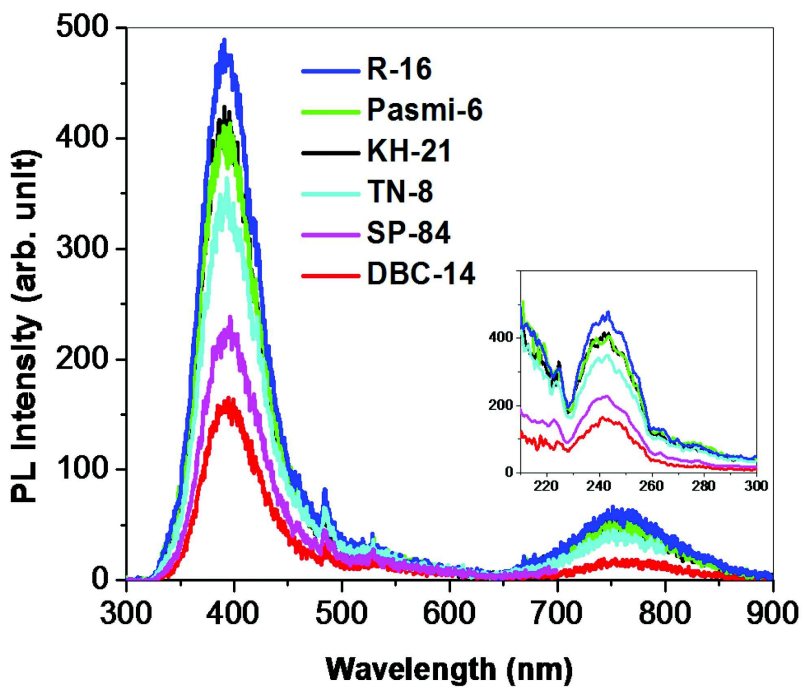

Fig. 5: PL emission spectra of quartz grains from different provenance showing a prominent peak at $395 \mathrm{~nm}$, inset shows the excitation spectra 
emission band around $760 \mathrm{~nm}$ is associated with the $\mathrm{Fe}^{3+}$ impurities [Yang and Mckeever, 1988; Pagonis et al., 2014]. The PL intensities varied over a factor of 4-5, whereas, the spectral shape/nature of the luminescence remained unchanged. This suggests that the recombination centres in samples, both dull and bright, were identical. Though the excitation energy and excitation mechanism are different in OSL and PL, the recombination centre is the same $\mathrm{H}_{3} \mathrm{O}_{4}^{\circ}$ type centre, which gives, $395 \mathrm{~nm}$ emission in both the cases. A correlation could be seen in the PL emission intensities with water content while taking into consideration the OSL sensitivities and the proportion of bright grains in the samples (Fig. 4, marked with red squares).

\section{Time Resolved Photoluminescence Decay}

PL decay of $395 \mathrm{~nm}$ emission of the quartz samples is shown in Fig. 6. Some samples like DBC14 and SP84 could be approximated using a single exponential decay curve, whereas, the samples like PASMI6, KH21 and TN8 showed an initial fast decay component followed by a second exponential decay. The decay time estimated from exponential fit equation falls in the range of $112 \pm 10 \mathrm{~ms}$ for all the samples in the linear decay region of the semi logarithmic plot. The decay times (1/?) of the two extreme samples in the FTIR spectrum (Fig. 1), SP84 and PASMI6 are 122 and $112 \mathrm{~s}$, respectively.

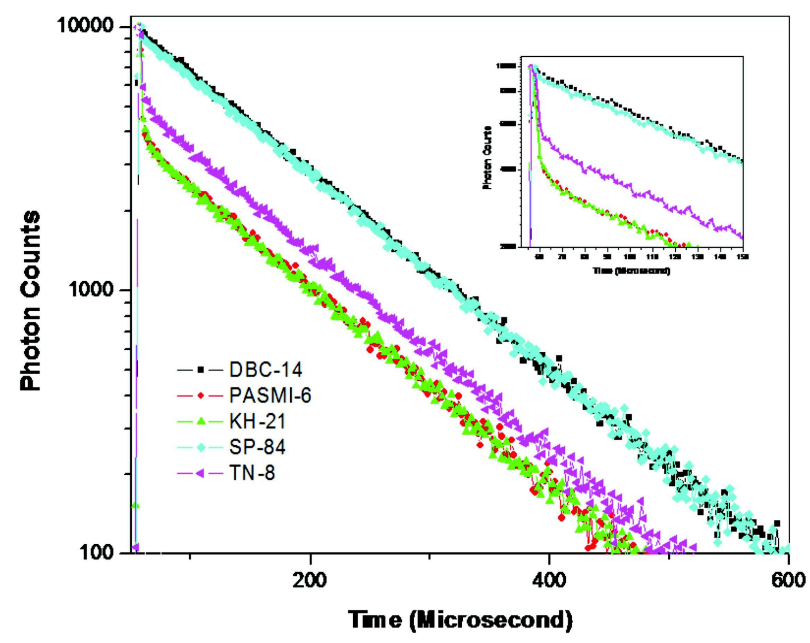

Fig. 6: PL decay of the quartz samples at emission wavelength $395 \mathrm{~nm}$ when excited by $242 \mathrm{~nm}$ UV light. The inset shows the initial part of decay exhibiting different behaviour for quartz samples
Since the emission cross-section is proportional to the luminescence efficiency and inversely on the luminescence decay time, a shortening of decay time o would increase the efficiency of emission. The luminescence decay pattern showed a correlation of the intensity of fast-relaxing component with the amount of water content and the OSL sensitivity. The normalised curves for different samples are presented in supplementary Fig. S4. As the intensity of OSL signal essentially is a measure of photon counts in the fast-decay region, the PL results also indicates that the water content in quartz is primarily responsible for varied OSL sensitivity/sample dependent sensitivity in natural quartz samples. Samples with lower water content generally indicated higher OSL sensitivity. The faster relaxing component suggests that this component gets quenched with the presence of water.

\section{Effect of Hydration on Luminescence}

Water resides in a quartz lattice as: a) $\mathrm{H}_{2} \mathrm{O}$ molecules contained as gas-liquid inclusions and absorbed onto the walls of microfactures within the quartz grain; and (b) structurally bound or crystallochemical water incorporated into the $\mathrm{SiO}_{4}$-framework forming a chemical bond with host. In FTIR spectra, $3000-3600 \mathrm{~cm}^{-1}$ is due to the fundamental $\mathrm{OH}-$ stretching vibrations of $\mathrm{H}_{2} \mathrm{O}$ molecule with two distinct absorption: i) sharp pleochroic peaks (due to presence of $\mathrm{OH}$ in structural sites), and (ii) broad isotropic band centred at $\sim 3400 \mathrm{~cm}^{-1}$ (due to incorporation of hydroxyl group) leading to glassy opal like microareas [Frondel, 1982]. Nuttal and Weil [1980] \& Weil [1984] probed the presence of two hole-trapped impurity centres namely $\left[\mathrm{H}_{3} \mathrm{O}_{4}\right]$ and $\left[\mathrm{H}_{4} \mathrm{O}_{4}\right]$. These are expected to be dominant in those grains which have larger hydroxyl content, whereas the corresponding centres in non-hydroxyl rich grains would be $\left[\mathrm{AlO}_{4} / \mathrm{M}^{+}\right]^{\circ}$ and $\left[\mathrm{AlO}_{4}\right]^{\circ}$ type-centres. It may be seen that the hydrogen containing radicals would have large vibrational contribution in their electronic excitation which contribute to predominant non-radiative relaxation of the excited species and these would be significantly less for $\left[\mathrm{AlO}_{4} / \mathrm{M}^{+}\right]^{\circ}$ and $\left[\mathrm{AlO}_{4}\right]^{\circ}$ type-centres. We believe that this is the main reason for the observed variation in the sensitivity of luminescence in natural quartz grains.

\section{Experimental Validation}

To check the validity of our suggestion that the 

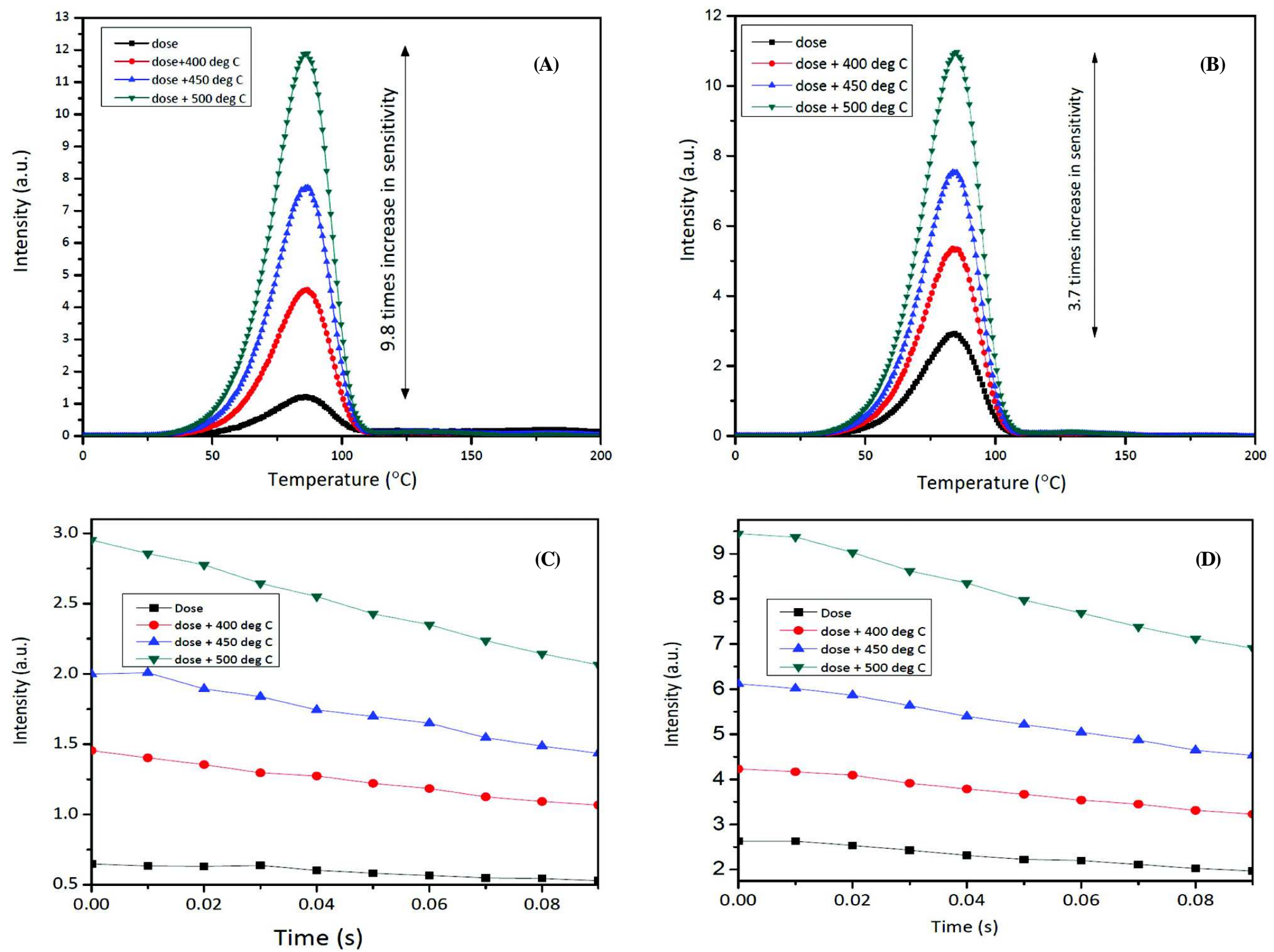

Fig. 7: Increase in (a,b) TL, and (c,d) OSL sensitivity in dull and bright quartz under combined dose + heating, respectively 
presence of water molecule, results in larger nonradiative relaxation of electronically excited centres during TL/OSL process, the luminescence sensitivity of dull and bright grains of samples SP84 were tested under controlled condition. Figure 7(A-D) shows results for weight normalized samples following the sequence, $\beta$-irradiation + heating $\left(400\right.$ to $\left.500^{\circ} \mathrm{C}\right)+$ TL. The test was performed at temperature lower than quartz phase transition temperature of $573^{\circ} \mathrm{C}$ $(\alpha \rightarrow \beta)$ in view of results of Poolton et al. [2000] who reported an increase in sensitivity above phase transition temperature with involvement of $\mathrm{Ti}$ associated donors and $\mathrm{Al}$ acceptors in OSL process. TL sensitivity of $110^{\circ} \mathrm{C}$ peak in dull quartz [Fig. 7(a)] increased $\sim 9.8$ times and it increased only by $\sim 3.7$ times for bright quartz [Fig. 7(b)].

Increase in OSL sensitivity for dull quartz samples was $\sim 4.8$ times and for bright quartz sample was $\sim 3.6$ times, as was measured using sequence $\beta$ irradiation + heating $\left(400\right.$ to $\left.500^{\circ} \mathrm{C}\right)+$ OSL [Fig. $7(\mathrm{C})$ and 7(D), respectively]. Variation in luminescence sensitivity could not be seen up to $240^{\circ} \mathrm{C}$ (used for preheat temperature), suggesting that the heating to temperatures higher than $240^{\circ} \mathrm{C}$ is necessary to induce sensitivity enhancement. These experimental results finally suggested that, higher the amount of water within quartz lattice, the lesser is its sensitivity because of higher number of aqua-complexes. This leads to larger increase in luminescence sensitivity upon dose + heating cycle. On the contrary, samples with low water in crystal lattice possess high initial sensitivity due to lesser number of aqua-complexes. The increase in luminescence sensitivity in bright samples on dose + heating cycle is limited in such cases.

Overall, we conclude that the luminescence sensitivity variation among samples from different sources depend upon the amount of water present/ trapped in the quartz crystal during crystallization

\section{References}

Bottern-Jensen L, Mckeever S W S and Wintle A G (2004) In: Optically Stimulated Luminescence Dosimetry, Elsevier Publications, ISBN: 0-444-50684-5

Bottern-Jensen L, Larsen N A, Mejdahl V, Poolton N R J, Morris MF and Mckeever S W S (1995) Luminescence sensitivity changes in quartz as a result of annealing Radiation Measurements 24 535-541 process. Upon suitable irradiation-heating cycle, the luminescence sensitivity of quartz crystals can be modified. A simple heating step is sufficient to increase the luminescence sensitivity of quartz samples used for dating purpose as the grains were already exposed to irradiation in nature during burial.

\section{Conclusions}

Conclusions from the present work are:

1. This study provides evidence that the presence of $\mathrm{H}_{2} \mathrm{O}$ in quartz lattice is anti correlated to luminescence sensitivity which can be explained using aqua-complex model. The samples with low sensitivity exhibit high water content and converse also holds.

2. Water and trace elements in quartz lattice form aqua-complexes. Such emission centres are in close proximity of $\mathrm{H}_{2} \mathrm{O}$ molecules which increases the non-radiative relaxation processes and alter the luminescence sensitivity.

3. Irradiation + heating plays a crucial role in the increase of TL/OSL sensitivity. A large increase in sensitivity of dull quartz samples as compared to bright quartz is associated with the removal of water from quartz lattice and formation of dislocations (charge trapping sites) upon heating.

\section{Acknowledgements}

The authors thank Prof. C M Sunta for useful comments. AKS thanks DST, India for J C Bose fellowship and the Department of Atomic Energy for Raja Ramanna Fellowship. SKS stay at PRL was supported by the contingency grant of J C Bose Fellowship to AKS. We respectfully dedicate this paper to the memory of Dr. K S V Nambi, who contributed immensely to the development of Luminescence dosimetry in India and at international level.

Chithambo M L, Preusser F, Ramseyer K and Ogundare F O (2007) Time-resolved luminescence of low sensitivity quartz from crystalline rocks Radiation Measurements $\mathbf{4 2}$ 205-212

Frondel C (1982) Structural hydroxyl in chalcedony (type B quartz) American Mineralogy 67 1248-1257

Gotze J, Plotze M and Habermann D (2001) Origin, spectral characteristics and practical applications of the 
cathodoluminescence (CL) of quartz - A review Mineralogy and Petrology 71 225-250

Han Z Y, Li S H and Tso M Y W (1997) Age dependence of luminescence signals from granitic and mylonitic quartz Quaternary science reviews 16 427-430

Krbetschek M, Gotze J and Trautmann T (1997) Spectral information from mineral relevant for luminescence dating Radiation Measurements 27 695-748

Kuhn R, Trautmann T, Singhvi A K, Krbetschek M R, Wagner G A and Stolz W (2000) A study of Thermoluminescence emission spectra and optical stimulation spectra of quartz from different provenances Radiation Measurements 32 653-657

Martini M, Fasoli M and Galli A (2009) Quartz OSL emission spectra and the role of $\left[\mathrm{AlO}_{4}\right]^{\circ}$ recombination centres Radiation Measurements 44 458-461

Martini M, Meinardi F, Rosetta E, Spinolo G and Vedda A (1995) Wavelength resolved thermally stimulated luminescence of $\mathrm{SiO}_{2}$ films Journal of Non-Crystalline Solids 187 124128

Mckeever S W S (1984) Thermoluminescence in Quartz and Silica Radiation Protection Dosimetry 8(1-2) 81-98

Nuttal R D and Weil J A (1980) Two hydrogenic trapped-hole species in $\alpha$-quartz Solid State Communications 33 99102

Pagonis V, Chithambo M L, Chen R, Chruœciñska A, Fasoli M, Li S H, Martini M and Ramseyer K (2014) Thermal dependence of luminescence lifetimes and radioluminescence in quartz Journal of Luminescence 145 $38-48$

Poolton N R J, Smith G M, Riedi P C, Bulur E, Botter-Jensen L, Murray A S and Adrian M (2000) Luminescence sensitivity changes in natural quartz induced by high temperature annealing: a high frequency EPR and OSL study Journal of Physics D: Applied Physics 33 1007-1017

Preusser F, Chithambo M L, Götte T, Martini M, Ramseyer K, Sendezera E J, Susino G J and Wintle A G (2009) Quartz as a natural luminescence dosimeter Earth Science Reviews 97 184-214

Rink W J (1994) Billion year age dependence of luminescence in granitic quartz Radiation measurements 23 419-422
Roy P, Balaram V, Kumar A, Satyanarayanan M and Rao T G (2007) New REE and Trace Element Data on Two International Kimberlitic Reference Materials by ICP-MS Geostandards and Geoanalytical Research 31(3) 261-273

Sawakuchi A O, Blair M W, Dewitt R, Faleiros F M, Hyppolito T and Guedes C C F (2011) Thermal history versus sedimentary history: OSL sensitivity of quartz grains extracted from rocks and sediments Quaternary Geochronology 6 261-272

Sawakuchi A O, Dewitt R and Faleiros F M (2011) Correlation between thermoluminescence sensitivity and crystallization temperatures of quartz: Potential application in geothermometry Radiation Measurements 46 51-58

Takashi Y, Tomoyuki T and Tetsuo H (2006) Dependence of luminescence sensitivities of quartz on $\alpha-\beta$-phase inversion break temperatures Radiation Measurements 41 841-846

Vartanian E, Guibert P, Roque C, Bechtel F and Schvoerer M (2000) Changes in OSL properties of quartz by preheating: An interpretation Radiation Measurements 32 647-652

W L Medlin (1968) The nature of traps and emission centers in thermoluminescent rock materials \& Thermoluminescence of Geological Materials, D. J. McDougall, ed., Academic Press, N. Y. 193-223

Weil J A (1984) A review of electron spin spectroscopy and its application to the study of paramagnetic defects in crystalline quartz Physics and Chemistry of Minerals 10 149-165

Yang X H and McKeever S W S (1990a) Point defects and the pre-dose effect in quartz Radiation Protection Dosimetry 33 27-30

Yang X H and McKeever S W S (1990b) The pre-dose effect in crystalline quartz Journal of Physics D: Applied Physics 23(2) 237-244

Yang X H and McKeever S W S (1988) Characterization of the pre-dose effect using ESR and TL, International Journal of Radiation Applications and Instrumentation. Part D. Nuclear Tracks and Radiation Measurements 14(1-2) 7579. 